\title{
Lower limb ischemia causing forefoot amputation post misdirected intra-muscular injection: A case
}

\section{report}

\author{
Parveen Kumar ${ }^{1}$, S S Panda*2, \\ 1 Department of Pediatric Surgery, Chacha Nehru Bal Chikitsalya, New Delhi, India; Email: parveenkumar_maan@yahoo.co.in \\ 2 Department of Paediatric Surgery, Maulana Azad Medical College, New Delhi, India \\ *Corresponding Author: Dr. S S Panda, Department of Paediatric Surgery, Maulana Azad Medical College, New Delhi-110002, \\ India, Email: drshasank_aiims@yahoo.co.in
}

Received: February 24, 2019; Published: March 28, 2019

\section{Abstract}

A misplaced intra-muscular injection and not following the basic guidelines of aspirating before injecting, may be devastating. We present here a case of 1.5 months old baby, who had ischemia of lower limb post misdirected i.m. injection outside and was managed strategically but at the cost of auto amputation of forefoot. This devastating outcome was avoidable by sound community practice.

Keywords: Ischemia, Gangrene, i.m. injection, Amputation.

\section{INTRODUCTION}

The placement of an intra-muscular injection is one of the basic skills executed by medical professionals. It is governed by basic rule of aspirating before injecting. A simple neglect may lead to devastating complications. We present here a case of right lower ischemia post misplaced i.m. injection and its management.

\section{CASE REPORT}

A one and half month-old baby born of full term normal vaginal delivery presented to a rural practitioner for routine immunization. He was given pentavalent i.m. vaccine in right thigh and sent home. The baby was crying in pain whole day but parents thought it may be due to vaccine itself and gave paracetamol syrup to baby. By 12 hours parents noticed reddish discoloration of right lower limb and baby was taken to doctor next day. He was prescribed some oral antibiotics and when symptoms did not subside, baby was referred to higher center. At presentation, baby was crying, restless with heart rate of $162 / \mathrm{min}$. The local examination of lower limb revealed a tender and cold periphery, with feeble popliteal pulses and absent dorsalis pedis pulsation. There were multiple necrotic changes on skin and gangrenous toes with ill-defined demarcation. Routine investigations revealed raised leucocyte counts of $23,000 / \mathrm{cmm}$ with $84 \%$ polymorphs and $\mathrm{C}$ reactive protein levels of $236 \mathrm{mg} / \mathrm{l}$. After initial resuscitation, baby was posted for wound debridement and multiple fasciotomies but toes were not amputated in view of ill-defined demarcation of gangrenous changes. With regular dressings and wound care, baby showed signs of improvement in form of accepting feeds, normalization of counts, serial decrease in CRP levels and good healthy granulation tissue (Fig.1 and Fig. 2). Pus culture and blood culture both had growth of MRSA (methicillin resistant staph aureus) for which baby received 14 days vancomycin. Right forefoot got auto amputated in course with regular dressings. Baby was discharged home in satisfactory condition and doing well in follow up.

\section{DISCUSSION}

Limb gangrene following inadvertent injection of various drugs are well documented in literature [1,2]. The various hypothesis postulated for limb gangrene in such conditions may include direct vascular insult, perivascular injury or inflammation, vasoconstriction caused by unintentional intra-arterial injection or intense vasospasm with embolization phenomenon $[3,4]$. The intense vasospasm theory may explain symptoms in our baby and distal embolic phenomenon may explain toe ischemia and gangrene in present case.

The initial response post debridement and fasciotomies was positive and decision for thrombolytic therapy was not taken. Literature states of use of various thrombolytic agents but without clear dosage, indications and duration of therapy [5]. 


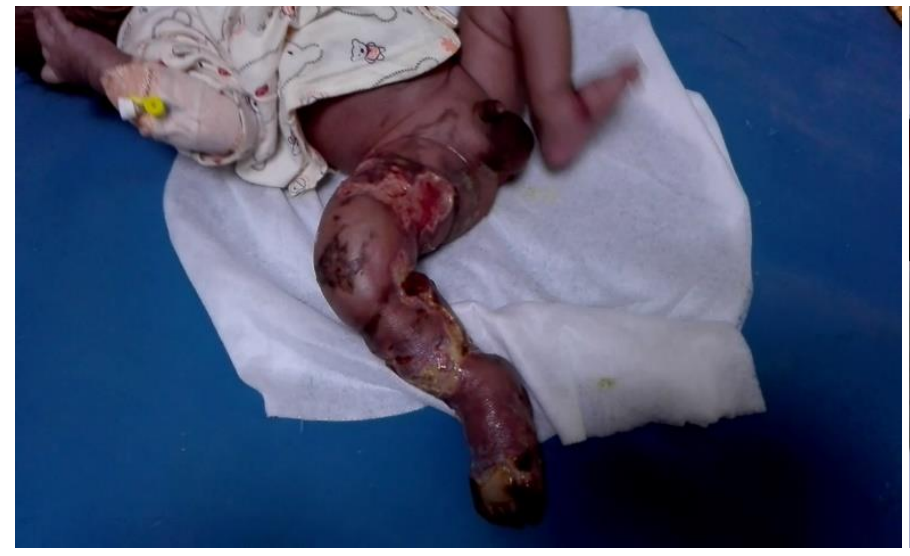

Fig 1: Right lower limb post debridement picture

\section{CONCLUSION}

This case is being presented here to bring the devastating complications of a simple injection to limelight, which is shearly preventable with safe vaccination guidelines and always aspirating before injecting.

\section{Acknowledgement}

The patient was managed at Lok Nayak Hospital affiliated to Maulana Azad Medical College.

\section{Conflict of Interest}

None declared

\section{Financial Support}

None declared

\section{REFERENCES}

1. Ghosh D, Saha S, Das S, Konar H. Limb gangrene following intramuscular injection of long acting penicillin. Journal of Indian Association of Pediatric Surgeons. 2002;7: 92-5.

2. Hajong R. Upper limb gangrene following intramuscular diclofenac: a rare side effect. Journal of surgical case reports. 2013 ;2: rjs039.

3. Kim SK, Kim TH, Lee KC. Nicolau syndrome after intramuscular injection: 3 cases. Arch Plast Surg 2012;39:249-52.

4. Sengupta $S$. Gangrene following intra-arterial injection of procaine penicillin. Aust N Z J Med 1976;6:71-3.

5. Yee DL, Chan AK, Williams S, Goldenberg NA, Massicotte MP, Raffini LJ. Varied opinions on thrombolysis for venous thromboembolism in infants and children: Findings from a survey of pediatric hematology-oncology specialists. Pediatr Blood Cancer 2009;53:960-6.

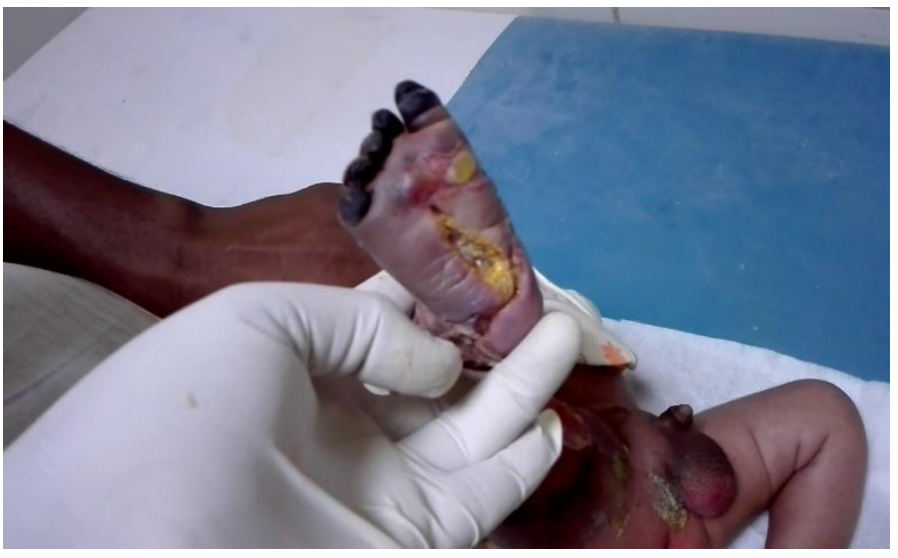

Fig 2: Fasciotomy wound in healing phase and demarcation setting in forefoot 